\title{
'n ONDERSOEK NA DIE VERBAND TUSSEN LEIERSKAPPOTENSIAAL EN SEKERE BIOGRAFIESE VERANDERLIKES ONDER 'N GROEP UNIVERSITEITSTUDENTE
}

\author{
A.M. VIVIERS \\ DEPARTEMENT BEDRYFSIELKUNDE \\ UNIVERSITEIT VAN STELLENBOSCH
}

\begin{abstract}
The study investigates whether university students, classified as leaders and non-leaders differ with respect to their responses to a number of biographical items. The results indicate that the following biographical variables do differentiate between leaders and non-leaders: educational qualifications and occupation of father, number of times the family moved, class position and leader activities during high school, parents' motivation of and interest in child, extent of freedom enjoyed during childhood, membership of social, religious and other organizations during high school, number of hobbies and extent of confidence experienced in strange situations. Not all the items were found to be equally relevant in die case of female and male leaders, however.
\end{abstract}

In enige organisasie behoort een van die belangrikste oogmerke van mannekragbestuur te wees die identifisering van mense met leierskappotensiaal wat later suksesvolle bestuurders kan word.

Swak leierskap is baie riskant vir " $\mathrm{n}$ organisasie. Deur die geskiedenis heen is herhaalde kere bewys dat die verskil tussen sukses en mislukking van organisasies grootliks saamhang met die kwaliteit van leierskap.

Dit kan verwag word dat die behoefte van leierskap in Suid-Afrika in die volgende aantal jare aansienlik sal toeneem as gevolg van die vinnige toename in die grootte van organisasies wat noodwendig bestuurders sal benodig om hul aktiwiteite te koördineer en te integreer.

Indien leierskappotensiaal vroegtydig geïdentifiseer kan word, kan heelwat voordeel daaruit getrek word. Dit kan meebring dat potensiële leiers vroeg reeds die regte opleiding,

\footnotetext{
*Tans by die Afdeling Mannekrag van die Suid-Afrikaanse Spoorweë, Johannesburg
} 
aanmoediging en ondersteuning kry om hul talente ten volle te ontwikkel en hul leierskapvermoëns positief uit te bou.

Die doel met hierdie studie is dan ook om sekere aspekte van leierskap verder te ondersoek en om te bepaal of leierskappotensiaal geredelik voorspel kan word.

Navorsers is al baie jare besig om die eienskappe te ondersoek wat die suksesvolle leier onderskei en gevolglik is lang lyste van eienskappe opgestel. Ongelukkig is daar groot variasie in hierdie lyste en kan daar nog nie ooreenstemming bereik word oor presies watter eienskappe in die lyste vervat moet word nie - heelwaarskynlik omdat faktore buite die individu ook in 'n sekere mate sy leiersvermoë bepaal. Wanneer leierskappotensiaal bestudeer word, kom hierdie faktore nie in die prent nie en word daar uiteraard gekonsentreer op die inherente eienskappe van die leier. Hierdie benadering hou opsigself heelwat meriete in.

Ghiselli kom na jare lange studie van leierskap (Korman, 1971, p. 123) tot die gevolgtrekking dat:

- $\quad$ daar ' $n$ aantal eienskappe bestaan wat verband hou met leierskapgedrag in formele organisasies, onafhanklik van situasieveranderlikes; en

- die eise wat 'n organisasie aan leierskaptalent stel dieselfde is vir alle bestuursposte, maar toeneem in belangrikheid namate hoër bestuursposte bereik word.

Hierdie besondere benadering is ook in die onderhawige gevolg, soos later duideliker sal blyk.

Met verloop van tyd is ook verskillende metodes ontwikkel om bestuurders te selekteer. Nie al die metodes is ewe effektief nie, maar dit kan tog gebruik word om ' $\mathrm{n}$ aanduiding te gee van leierskappotensiaal. Guion (1965) noem 'n aantal tegnieke soos spesiale toetse vir toesighouers, algemene toetse wat sekere leierseienskappe en motivering meet, nominasies van gelykes, persoonlike data en persoonlike beoordeling. In 1971 het Ghiselli 'n kort selfbeskrywingsvraelys ontwikkel (die SDI) wat volgens Gannon (1977) die eienskappe van leiers suksesvol kan meet. 'n Meer kontemporêre metode wat gebruik word om bestuurspotensiaal te identifiseer, is die takseersentrum ("Assessment Centre").

Biografiese gegewens word ook dikwels gebruik in leierskapstudies. Die begrip "biografiese gegewens" verwys na die omstandighede, ondervindings en gebeure in die 
lewensloop van 'n bepaalde individu en dui dus in 'n sekere sin die lewensgeskiedenis van 'n spesifieke individu aan.

Die vraag onstaan watter eienskappe deur middel van biografiese vraelyste ondersoek kan word. 'n Studie deur Fick (1977) toon aan dat biografiese inligting gebruik kan word om 'n groot verskeidenheid kriteria te voorspel. Biografiese gegewens kan volgens hom ook baie handig gebruik word as voorspeller van leierskap en werksukses. Coetsee (1973) kom in sy studie tot die gevolgtrekking dat biografiese vraelyste " $n$ geldige en waardevolle instrument is by navorsing na eienskappe van bestuurders. Wald en Doty (1954) kom ook in hul studie van topbestuurders tot die gevolgtrekking dat daar 'n definitiewe agtergronds- en persoonlikheidspatroon is wat suksesvolle bestuurders kenmerk en dat dit effektief met behulp van biografiese inligting omlyn kan word.

Aangesien dit met 'n redelike mate van sekerheid aanvaar kan word dat leiers oor basiese gemeenskaplike, meetbare eienskappe beskik, (soos vroeër aangedui) het die vraag ontstaan of leiers verskil ten opsigte van sekere agtergrondfaktore. Dus, in hoe 'n mate stem die agtergrondinligting, dit wil sê biografiese data van leiers ooreen? Anders gestel, watter verwantskap bestaan daar tussen leierskappotensiaal en sekere biografiese data? Hierdie vraag vervat die probleemstelling van die onderhawige studie en het aanleiding gegee tot die stel van die volgende hipotese om die verband wat daar tussen die veranderlikes is, te probeer bepaal naamlik: Leiers en nie-leiers verskil nie beduidend ten opsigte van 'n groep geselekteerde biografiese veranderlikes nie.

\section{METODE}

Dit sou dus nodig wees om proefpersone te verdeel in 'n leiersgroep en 'n nieleiersgroep en dan vas te stel wat se biografiese items tussen die twee groepe onderskei.

Om die nodige inligting te verkry is twee vraelyste gebruik. Die een is " $\mathrm{n}$ gestandaardiseerde vraelys van Ghiselli, die "Self-Description Inventory" en die ander is 'n Biografiese en Kontemporêre Inligtingsvraelys wat vir die doel van hierdie studie opgestel is.

\section{Die Self-Description Inventory (SDI)}

Die onderhawige studie het vereis dat daar 'n onderskeid gemaak moes word tussen leiers en nie-leiers of volgelinge. Aangesien die SDI (soos saamgestel deur Ghiselli, 1971) 
reeds in verskeie navorsing gebruik is en as 'n geskikte en geldige instrument bevind is, is daar besluit om dit vir hierdie studie te gebruik.

Die doel van die SDI is om eienskappe van bestuurders of leiers te beoordeel en nie die persoon self nie. Dit geskied deurdat proefpersone volgens 'n gedwonge keusetegniek hulself moet beskryf deur 'n alternatief uit 64 pare byvoeglike naamwoorde te kies.

Die 64 pare woorde vervat 13 skale wat sielkundige eienskappe van bestuurders aandui. Op grond van die totale telling van 'n persoon word die persoon dan geklassifiseer as leier of volgeling. Die 13 skale kan in die volgende kategorieë verdeel word.

\section{VERMÖ̈NS}

- Toesighouvermoë

- Intelligensie

- Inisiatief

\section{PERSOONLIKHEIDSEIENSKAPPE}

- Selfvertroue

- Beslistheid

- Manlikheid - Vroulikheid

- Volwassenheid

- Werkklasverwantskap

\section{MOTIVERING}

- Behoefte aan beroepsprestasie of beroepsukses

- Behoefte aan selfaktualisering

- Behoefte aan mag oor ander

- Behoefte aan hoë finansiële vergoeding

- Behoefte aan werksekuriteit

Bogenoemde eienskappe hou almal in 'n meerdere of mindere mate verband met bestuurstalent volgens Ghiselli (1971) se studies. Sommige van hierdie eienskappe toon 'n baie sterk verband, terwyl ander egter 'n minder sterk verband aandui. 
Biografiese en Kontemporêre Inligtingsvraelys

Dit was ook nodig om 'n vraelys te ontwikkel om data omtrent die proefpersone se agtergrond en huidige status te verkry.

Die vraelys bestaan uit 30 vrae met ' $n$ aantal alternatiewe. Die multi-keusebenadering word gebruik en 'n proefpersoon moet 'n vraag beantwoord deur een van die alternatiewe te kies. Items 2 tot 30 het almal betrekking op biografiese en kontemporêre data omtrent die proefpersoon. Item 1 dui die persoon se geslag aan.

Die items wat in die vraelys gebruik is, is verkry uit die volgende bronne: Die "Catalog of Life History Items" van Glennon, Albright en Owens (1966) en die biografiese vraelyste van Fick (1977), Lätti (1972) en Coetsee (1973). Ander items is spesifiek opgestel vir gebruik in hierdie ondersoek.

Die items dek ' $n$ wye reeks faktore wat moontlik verband hou met leierskappotensiaal. Die faktore sluit onder andere in: Demografiese data, huislike agtergrond en verhoudings, kwalifikasies en beroep van ouers, invloed van godsdiens, leiersposisies beklee op skool en universiteit, deelname aan sport en kulturele aktiwiteite en gesondheidstoestand.

Die meeste items is in die vraelys ingesluit op grond van ander studies wat reeds hul verband met leierskaptalent of bestuurspotensiaal toon. Ander items is ingesluit omdat daar verwag is dat daar moontlik 'n verband tussen die items en leierskappotensiaal kan bestaan.

\section{Monster}

Die data wat in hierdie ondersoek verkry is, is afkomstig van drie groepe studente aan die Universiteit van Stellenbosch, naamlik 165 Bedryfsielkundestudente, 20 Huishoudkundestudente en 30 studente van die Nagraadse Bestuurskool (MBA-studente).

Om te bepaal of die resultate eksterne geldigheid sou besit, dit wil sê veralgemeenbaar sou wees, is die monster opgedeel in twee hoofgroepe: die Bedryfsielkundestudente het Groep I gevorm en die Huishoudkunde- en MBA-studente Groep II. Die twee hoofgroepe is elk in twee verdere groepe verdeel sodat dit 'n groep mans en 'n groep dames verteenwoordig. Hierdie verdere verdeling was nodig om die moontlike effek van kontaminasie van geslag uit te skakel, aangesien leierskapnorms vir die twee geslagte kan verskil.

Die SDI en die Biografiese vraelys is gelyktydig aan die proefgroepe geadministreer. 'n Aantal van die vraelyste wat voltooi is moes verwerp word omdat dit nie volledig voltooi is 
nie. 'n Totaal van 27 uit die 215 vraelyste of $12,5 \%$ is verwerp en 188 of $87,5 \%$ was bruikbaar.

\section{Verwerking van Resultate}

\section{Die SDI}

Die vraelyste is nagesien deur gebruikmaking van verskillende maskers wat ontwerp is om die 13 eienskappe op die SDI te meet. Slegs die volgende ses eienskappe (ongeveer die helfte van die oorspronklike) wat die meeste bydra tot bestuursukses is met behulp van die maskers verkry: toesighouvermoë, beroepsprestasie, intelligensie, selfaktualisering, selfvertroue en beslistheid.

Ghiselli (1971) vind dat die relatiewe belangrikheid van die eienskappe tot bestuurstalent verskil. Om kwantitatiewe waardes te verkry vir elke eienskap se bydrae tot bestuurstalent, het hy van 'n skatting (evaluasie-waarde) gebruik gemaak deur elke eienskap aan drie kriteria te toets. Om die grootte van die bydrae van elke eienskap tot bestuurstalent te bereken is die tellings wat op die eienskappe verkry is vermenigvuldig met die betrokke eienskap se evaluasie-waarde soos deur Ghiselli bepaal. Die rasionaal hieragter is dat 'n blote sommering van routellings nie heeltemal korrekte weergawe sou gee van 'n persoon se leiersvermoë nie. 'n Hoë telling op die een eienskap sou opmaak vir 'n lae telling op 'n ander eienskap. Deur dus elke eienskap se routelling met die betrokke konstante (evaluasie-waarde) te vermenigvuldig, word sodanige kompensasie uitgeskakel. Die tellings van die ses eienskappe wat sodoende verkry is, is gesommeer om die totale leierskaptelling van elke proefpersoon te verkry.

Om afsnypunte te bepaal vir leiers en nie-leiers, is Kelly (1939) se "Upper-lower 27 percent method" gebruik. Hiervolgens word die boonste $27 \%$ en die onderste $27 \%$ van die tellings van die proefpersone gebruik om die twee eksperimentele groepe te verteenwoordig.

Die boonste groep het hoë tellings en verteenwoordig die persone met leierskappotensiaal, terwyl die onderste groep lae tellings het en die persone verteenwoordig wat nieleiers is.

\section{Die Biografiese en Kontemporêre Inligtingsvraelys}

Die gegewens wat deur middel van die vraelys ingesamel is, is verwerk deur eerstens die frekwensies vir elke item ten opsigte van elke groep te tabelleer. Hierdie frekwensietabelle het die nodige data voorsien wat nodig was vir verdere ontledings. 
Om te bepaal of daar enige beduidende verskille in frekwensies tussen leiers en nieleiers ten opsigte van die items op die biografiese vraelys bestaan, is Chikwadraatwaardes bereken.

Om verdere gevolgtrekkings te kon maak, is die items wat beduidend tussen leiers en nie-leiers onderskei het, se korrelasies met die kriterium (prestasie op die SDI) bereken. Die interkorrelasies van die diskriminerende items is ook bereken sodat ' $\mathrm{n}$ matriks opgestel kon word waaruit 'n meervoudige korrelasie bereken kon word ten einde vas te stel hoedanig leierskappotensiaal met behulp van biografiese data "voorspel" kan word.

\section{RESULTATE EN BESPREKING}

\section{SDI-Inligting}

Gegewens oor die prestasie van die vier groepe op die SDI van Ghiselli verskyn in Tabel 1.

\section{$\underline{\text { TABEL } 1}$}

GEMIDDELDES EN STANDAARDAFWYKINGS VAN DIE SDI

\begin{tabular}{|l|c|c|c|c|}
\hline GROEP & $\begin{array}{c}\text { LAAGSTE } \\
\text { TELLING }\end{array}$ & $\begin{array}{c}\text { HOOGSTE } \\
\text { TELLING }\end{array}$ & $\bar{X}$ & $\mathrm{~s}$ \\
\hline Groep I & & & & \\
$\quad$ Bedryfsielkunde mans & 67 & 143,4 & 106,92 & 18,26 \\
Bedryfsielkunde dames & 53,1 & 154,6 & 105,77 & 20,20 \\
Groep II & & & & \\
MBA (mans) & 91,8 & 144,6 & 111,00 & 14,30 \\
Huishoudkunde (dames) & 73,8 & 150,9 & 112,38 & 17,66 \\
\hline
\end{tabular}

Die hoogste en laagste tellings van elke groep proefpersone dui 'n groot omvang aan, sodat die leiers en nie-leiergroep ver van mekaar op die kontinuum van tellings lê. As die grootte van die standaardafwykings ook in ag geneem word, kan daar tot die gevolgtrekking gekom word dat die leiers- en nie-leiersgroepe grootliks van mekaar verskil.

Indien die hoogste en laagste tellings vir elke groep proefpersone vergelyk word met die res van die resultate in Tabel 1, blyk dit dat al 4 groepe ' $n$ redelik normale verspreiding toon. Hieruit kan afgelei word dat die SDI 'n "verteenwoordigende" monster leiers en nieleiers opgelewer het. Daar kan dus aanvaar word dat die SDI 'n geskikte metode was vir die identifisering van leierskappotensiaal in die onderhawige studie. 


\section{Biografiese inligting}

Chi-kwadraatwaardes wat beduidende frekwensieverskille aandui tussen leiers en nieleiers op die biografiese items, verskyn in Tabel 2. (By die MBA-mans was daar geen beduidende verskille tussen leiers en nie-leiers nie).

\section{TABEL 2}

\section{ITEMS VAN DIE BIOGRAFIESE VRAELYS WAT ONDERSKEI TUSSEN LEIERS EN NIE-LEIERS}

\begin{tabular}{|c|c|c|c|}
\hline ITEM & \multicolumn{3}{|c|}{$x^{2} a$} \\
\hline NR. & $\begin{array}{c}\text { BEDRYFSIELKUNDE } \\
\text { MANS }\end{array}$ & $\begin{array}{c}\text { BEDRYFSIELKUNDE } \\
\text { DAMES }\end{array}$ & $\begin{array}{c}\text { HUISHOUDKUNDE } \\
\text { DAMES }\end{array}$ \\
\hline 18 & $11,16^{*}$ & & \\
\hline 21 & $7,19^{*}$ & & \\
\hline 22 & $6,53^{\mathrm{a} *}$ & & \\
\hline 27 & $10.81 *$ & & \\
\hline 28 & $6,54 *$ & $5,00 * *$ & \\
\hline 8 & & $11,06^{*}$ & \\
\hline 10 & & $8,82 * *$ & \\
\hline 12 & & $9,02 * *$ & $8,00 * *$ \\
\hline 24 & & $3,68^{\mathrm{a} * *}$ & \\
\hline 19 & & & $6,28 * *$ \\
\hline 25 & & & $4,66^{* *}$ \\
\hline $\begin{array}{l}\mathrm{a} \\
* \\
* *\end{array}$ & $\begin{array}{l}\text { Korreksie van Yates } \\
p<, 05 \\
p<, 10\end{array}$ & is gebruik & \\
\hline
\end{tabular}

Die gegewens in Tabe1 2 dui aan dat daar 11 items in die biografiese vrae1ys was wat beduidend onderskei tussen 1eiers en nie-1eiers. Op grond van hierdie gegewens kan die hipotese wat geste1 is, gedeeltelik verwerp word en we1 ten opsigte van die volgende items: $8,10,12,18,19,21,22,24,25,27$ en 28.

Hierdie items dek die vo1gende biografiese aspekte:

Items 8 en 10 - Aanta1 kwalifikasies en beroep van die vader.

Item 12 - Aanta1 kere wat 'n gesin verhuis het.

Items 18 en 19 - Klasposisie en leiersaktiwiteite gedurende hoërskoo1.

Items 21 en 22 - Ouers se motivering en belangstelling in die kind.

Item 24 - Mate van vryheid wat die persoon toegelaat is as kind. 
Item 25 - Deelname aan sosiale, godsdienstige en ander organisasies gedurende hoërskool.

Item 27 - Aanta1 stokperdjies beoefen.

Item $28 \quad-$ Se1fvertroue in vreemde situasies.

Die korrelasies wat bereken is tussen leierskappotensiaa1 en items wat beduidend onderskei het tussen leiers en nie-leiers, verskyn in Tabe1 3.

$\underline{\text { TABEL } 3}$

PRODUK-MOMENT KORRELASIES TUSSEN LEIERSKAPPOTENSIAAL EN STATISTIES BEDUIDENDE ITEMS VIR DIE VERSKILLENDE PROEFGROEPE

\begin{tabular}{|c|c|c|c|}
\hline ITEM & \multicolumn{3}{|c|}{$\mathrm{r}$} \\
\hline NR. & $\begin{array}{c}\text { BEDRYFSIELKUNDE } \\
\text { MANS }\end{array}$ & $\begin{array}{c}\text { BEDRYFSIELKUNDE } \\
\text { DAMES }\end{array}$ & $\begin{array}{c}\text { HUISHOUDKUNDE } \\
\text { DAMES }\end{array}$ \\
\hline 18 &, $23^{* *}$ & & \\
21 &, $24^{*}$ & & \\
22 &, 18 &, $36^{*}$ & \\
27 &, 11 &, $46^{*}$ & \\
28 &, 16 &, $42^{*}$ &,- 39 \\
8 & &, $34^{* *}$ & \\
12 & &, 25 & \\
24 & &, 15 & \\
$10 \mathrm{a}$ & &,- 19 & \\
$10 \mathrm{~b}$ & &,- 24 & \\
$10 \mathrm{c}$ & & & \\
$10 \mathrm{~d}$ & & & \\
25 & & & \\
$* \mathrm{p}<, 01$ & & & \\
$* * \mathrm{p}<, 05$ &
\end{tabular}

Die interkorrelasies van die items in Tabel 3 is gebruik om die meervoudige korrelasies wat in Tabel 4 verskyn vir drie groepe afsonderlik te bereken. 
TABEL 4

\section{MEERVOUDIGE KORRELASIES TUSSEN LEIERSKAPPOTENSIAAL EN BIOGRAFIESE ITEMS VIR DIE VERSKILLENDE PROEFGROEPE}

\begin{tabular}{l|c|c|}
\hline \multicolumn{1}{|c|}{ GROEP } & $\mathrm{R}$ & GEKRIMPTE $\mathrm{R}$ \\
\hline Bedryfsielkunde mans & $0,37^{*}$ & 0,31 \\
Bedryfsielkunde dames & $0,72^{*}$ & 0,66 \\
Huishoudkunde dames & 0,43 & 0,29 \\
\hline $\mathrm{p} \leq, 01$
\end{tabular}

Uit Tabel 4 blyk dit dat biografiese veranderlikes die sterkste verband hou met die leierskappotensiaal van Bedryfsielkunde dames. Daarna volg Bedryfsielkunde mans. Indien krimping in aanmerking geneem word, is Bedryfsielkunde dames nog steeds bo-aan.

Aangesien Bedryfsielkunde dames se korrelasie soveel sterker is as die van Bedryfsielkunde mans, kan daar aanvaar word dat die leierskappotensiaal van hierdie dames in 'n groot mate afhang van sekere biografiese faktore. Hierdie idee kan nie so sterk ondersteun word by Bedryfsielkunde mans nie, alhoewel biografiese faktore ook 'n invloed op hierdie persone se leierskappotensiaal kan hê.

Omdat daar slegs 'n geselekteerde aantal biografiese veranderlikes in die studie gebruik is, kan daar dus nie veralgemeen word wat betref bogenoemde nie. Die resultate wat in hierdie ondersoek verkry is, het dus slegs betrekking op die biografiese veranderlikes wat gebruik is.

\section{GEVOLGTREKKINGS}

Op grond van die resultate van hierdie studie word die volgende gevolgtrekkings gemaak:

1. Leiers en nie-leiers verskil ten opsigte van sekere biografiese veranderlikes wat met leierskap verband hou.

- Leiers en nie-leiers onder mans en dames verskil ten opsigte van onderskeidende biografiese veranderlikes.

- Bedryfsielkunde en Huishoudkunde dame-leiers en nie-leiers verskil ten opsigte van onderskeidende biografiese veranderlikes.

2. Biografiese veranderlikes hou verband met leierskappotensiaal. 
- Sekere biografiese faktore toon 'n baie sterk verband met die leierskappotensiaal van Bedryfsielkunde dames.

- Sekere biografiese faktore hou verband met die leierskappotensiaal van

Bedryfsielkunde mans en Huishoudkunde dames.

Uit hierdie studie het dit duidelik geword dat leiers en nie-leiers verskil ten opsigte van sekere biografiese veranderlikes en dat biografiese faktore verband hou met leierskappotensiaal.

Leiers en nie-leiers onder Bedryfsielkunde mans verskil wat betref hul akademiese prestasie en die mate van belangstelling wat hul ouers getoon het in hul akademiese prestasie. Leiers het beduidend hoër presteer en het meer belangstelling en aanmoediging gekry as nieleiers. Hierdie faktore hou dan ook die sterkste verband met leierskappotensiaal. Verder verskil hulle ook op grond van die mate van motivering wat hulle verkry van hul ouers tot verdere studie, die aantal stokperdjies wat hulle beoefen en die mate van selfvertroue wat hulle in vreemde situasies het. Leiers is beduidend meer gemotiveer, beoefen meer stokperdjies en tree met meer selfvertroue op.

Leiers en nie-leiers onder Bedryfsielkunde dames verskil beduidend wat betref die opvoedkundige kwalifikasies van die vader, die aantal kere verhuis, die mate van vryheid toegelaat as kind en die mate van selfvertroue in vreemde situasies. Leiers se vaders het hoër kwalifikasies, hul het meer verhuis, is meer vryheid toegelaat en tree met meer selfvertroue op as nie-leiers. Hierdie faktore hou die sterkste verband met leierskappotensiaal. Verder verskil leiers en nie-leiers ook wat betref die beroep van die vaders. Leiers se vaders beklee hoofsaaklik professionele en bestuursposte, terwyl die van nie-leiers laervlak poste beklee.

Leiers en nie-leiers onder Huishoudkunde dames verskil beduidend wat betref die aantal kere verhuis, die leiding geneem in aktiwiteite op skool en die mate van deelname in sosiale, godsdienstige en ander organisasies gedurende hoërskooljare. Leiers het minder verhuis, het minder die leiding geneem in aktiwiteite en het minder deelgeneem aan aktiwiteite op hoërskool. Hierdie resultate is die teenoorgestelde van wat verwag kan word en stem nie ooreen met bevindings van ander studies nie.

MBA mans verskil nie beduidend ten opsigte van die biografiese veranderlikes nie. Hierdie groep is redelik homogeen wat betref biografiese faktore. 
Uit die resultate blyk dus dat verskillende biografiese faktore verskillend bydra tot leierskappotensiaal by verskillende groepe. Mans en dames se leierskapspotensiaal word nie deur dieselfde biografiese faktore beïnvloed nie en selfs dames onderling word ook nie deur dieselfde faktore beïnvloed nie.

Biografiese faktore beïnvloed dus die leierskappotensiaal van verskillende persone op verskillende maniere. Aangesien hierdie studie van beperkte omvang is, is verdere navorsing eers nodig voordat sekere gevolgtrekkings veralgemeen kan word.

Verdere navorsing is nodig om te bepaal in hoe 'n mate hierdie gevolgtrekkings ook vir ander groepe geld. Daar sal gebruik gemaak moet word van groter monsters en die groepe behoort ook uitgebrei te word na universiteitstudente wat ander kursusse volg. Verder kan die biografiese vraelys ook uitgebrei word om meer inligting te bekom.

Indien die monster dus vergroot word en uitgebrei word na ander kursusse en die biografiese vraelys meer inligting insamel, kan daar gevolgtrekkings gemaak word wat veralgemeen kan word vir alle universiteitstudente. Hierdeur sal 'n duideliker beeld gekry kan word van die biografiese faktore wat bydra tot leierskappotensiaal.

\section{OPSOMMING}

In die ondersoek word nagegaan of universiteitstudente wat as leiers en nie-leiers geklassifiseer kan word ook verskil wat betref sekere biografiese en kontemporêre data. Die resultate dui daarop dat die volgende biografiese items wel onderskei tussen leiers en nie-leiers: Opvoedkundige kwalifikasies en beroep van vader, aantal kere wat 'n gesin verhuis het, klasposisie en leieraktiwiteite gedurende hoërskooljare, ouers se motivering en belangstelling in kind, mate van vryheid wat die persoon as kind toegelaat is, deelname aan sosiale, godsdienstige en ander organisasies gedurende hoërskooljare, aantal stokperdjies beoefen en selfvertroue in vreemde situasies. Al die items is egter nie ewe relevant in die geval van mans en damesleiers nie.

\section{VERWYSINGS}

Coetsee, L.D. 'n Biografiese en Psigologiese Profiel van 'n Aantal Suid-Afrikaanse Bestuurders. Ongepubliseerde Doktorale Proefskrif, Potchefstroomse Universiteit vir Christelike Hoër Onderwys, 1973. 
Fick, L.J. 'n Bedryfsielkundige Ondersoek na die Seleksie en Opleiding van Rekenaarstelselontleders. Ongepubliseerde Doktorale Proefskrif, Universiteit van Stellenbosch, 1977.

Gannon, M.J. Management: An Organizational Perspective. Boston: Little, Brown \& Company, 1977.

Ghiselli, E.E. Explorations in Managerial Talent. California: Goodyear Publishing Company, 1971.

Glennon, J.R., Albright, L.E. \& Owens, W.A. A Catalog of Life History Items. American Psychological Association, Division 14, 1966.

Guion, R.M. Personnel Testing. New York: McGraw-Hill, 1965.

Kelley, J.L. The selection of upper and lower groups for the validation of test items. Journal of Educational Psychology, 1939, 30, 17-24.

Korman, A.K. Industrial and Organizational Psychology. New Jersey: Prentice-Hall, 1971.

Lätti, V.I. Die Voorspelling van Skolastiese Sukses met behulp van Biografiese Gegewens. Pretoria: RGN-verslag nr. MT-11, 1972.

Wald, R.M. \& Doty, R.A. The top executive - a firsthand profile. Harvard Business Review, 1954, 32(4), 45-54. 